\title{
Asymptomatic Lymphogranuloma Venereum in Men who Have Sex with Men, United Kingdom
}

\section{Cara Saxon, Gwenda Hughes, Catherine Ison, for the UK LGV Case-Finding Group ${ }^{1}$}

We investigated prevalence of lymphogranuloma venereum (LGV) among men who have sex with men who were tested for chlamydia at 12 clinics in the United Kingdom during 10 weeks in 2012. Of 713 men positive for Chlamydia trachomatis, 66 (9\%) had LGV serovars; $15(27 \%)$ of 55 for whom data were available were asymptomatic.

$\mathrm{L}$ ymphogranuloma venereum (LGV) is a sexually transmitted infection (STI) caused by the L1, L2, and L3 serovars of Chlamydia trachomatis (CT). An LGV outbreak among men who have sex with men (MSM) first reported in the Netherlands in 2003 has since spread across other industrialized countries (1). Cases are typically seen among white, HIV-positive MSM who report unprotected anal intercourse, other high-risk behaviors, and STI co-infection and who commonly have symptoms of proctitis (i.e., rectal pain, rectal discharge, bloody stools, constipation, and tenesmus) (2).

The United Kingdom now has the largest documented outbreak of LGV among MSM worldwide (3,4). Infection control in England has relied on CT DNA typing and treatment of symptomatic MSM who have CT-positive rectal infections and their contacts, as well as health promotion. These measures were supported by a large prospective study in the United Kingdom during 2006-2007 that reported $<6 \%$ of LGV CT infections were asymptomatic (5). However, studies in the Netherlands and Germany, and a smaller UK study, have reported higher proportions $(17 \%-$ $53 \%$ ) of asymptomatic infection (6-8). We reinvestigated the prevalence of asymptomatic LGV CT infection among MSM in the United Kingdom to assess whether it may be sustaining the current epidemic.

\section{The Study}

In the UK, STI clinics are open access and provide free testing and treatment. Regular STI and HIV screening is encouraged for sexually active MSM with or without symptoms (9). A full medical and sexual history are recorded for all patients, and a physical examination is done for those with symptoms.

Twelve UK STI clinics participated; all serve cities with large MSM populations and routinely screen MSM for CT by examining urine or swab samples of the pharynx,

Author affiliation: Public Health England, London, UK

DOI: http://dx.doi.org/10.3201/eid2201.141867

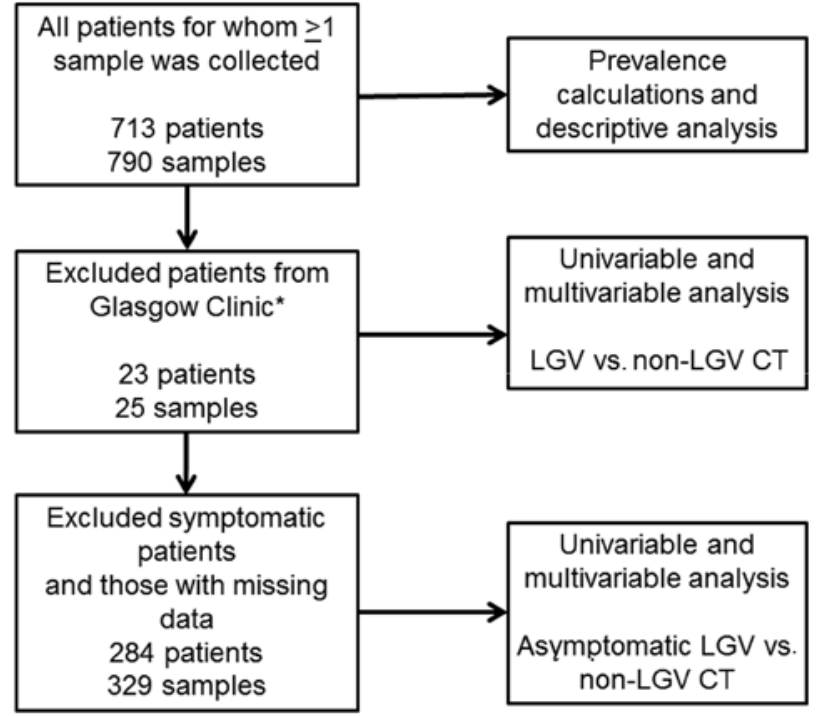

Figure. Data analysis flowchart for univariable and multivariable analyses of symptomatic lymphogranuloma venereum (LGV) versus non-LGV Chlamydia trachomatis (CT) infection (Table 1) and asymptomatic LGV versus non-LGV CTinfection (Table 2) in men who have sex with men, United Kingdom. *Patients from Glasgow were excluded from risk factor analyses because they do not routinely report to the Genitourinary Medicine Clinic Activity Dataset.

urethra, and rectum (either clinician-obtained or self-taken) according to UK guidelines (10). All MSM tested for CT during September 24-December 7, 2012, were included except those who had received antibiotic drugs during the previous 6 weeks.

More than $10,000 \mathrm{CT}$ tests were performed during the study period. Local laboratories performed routine testing for $\mathrm{CT}$ and referred all positive specimens from study participants to the Sexually Transmitted Bacteria Reference Unit of the national reference laboratory in London to test for LGV. At the reference laboratory, all specimens underwent extraction by using the Roche MagNA Pure LC extractor (Roche Diagnostics, Indianapolis, IN, USA), then CT confirmation by using a plasmid targeted real-time PCR and an LGV-specific real-time PCR targeting the $p m p H$ deletion on the RotorGene (QIAGEN, Valencia, CA, USA). Details of the LGV reference service were previously published (11).

Clinical data for symptoms were submitted for all study participants to Public Health England (PHE) through a

${ }^{1}$ Additional members of the UK LGV Case-Finding Group who contributed to data collection, analysis, and manuscript review are listed at the end of this article. 
secure web portal (online Technical Appendix Figure, http:// wwwnc.cdc.gov/EID/article/22/1/14-1867-Techapp1.pdf). Patients reporting symptoms at first medical examination or follow-up were defined as symptomatic. Those with no symptoms at first examination or follow-up were defined as asymptomatic. Additional clinical data were available from the national anonymized patient-level electronic surveillance system (the Genitourinary Medicine Clinic Activity Dataset [GUMCADv2]), which records all tests and diagnoses in STI clinics in England (12).

PHE has authority to collect anonymized patient-level data for public health monitoring and infection control. The study was reviewed in PHE's research and development office and deemed to fit this criterion.

We used univariable and multivariable logistic regression modeling in STATA version 13.1 (StataCorp LP, College Station, TX, USA) to investigate risk factors associated with LGV versus non-LGV CT infection and asymptomatic versus symptomatic LGV. A clinic in Glasgow, Scotland, was excluded from risk factor analyses because it does not report GUMCADv2 (Figure).

During the study period, 921 eligible specimens were received for DNA typing. On confirmatory testing, 90 (10\%) specimens were CT negative, 36 (4\%) inhibitory,

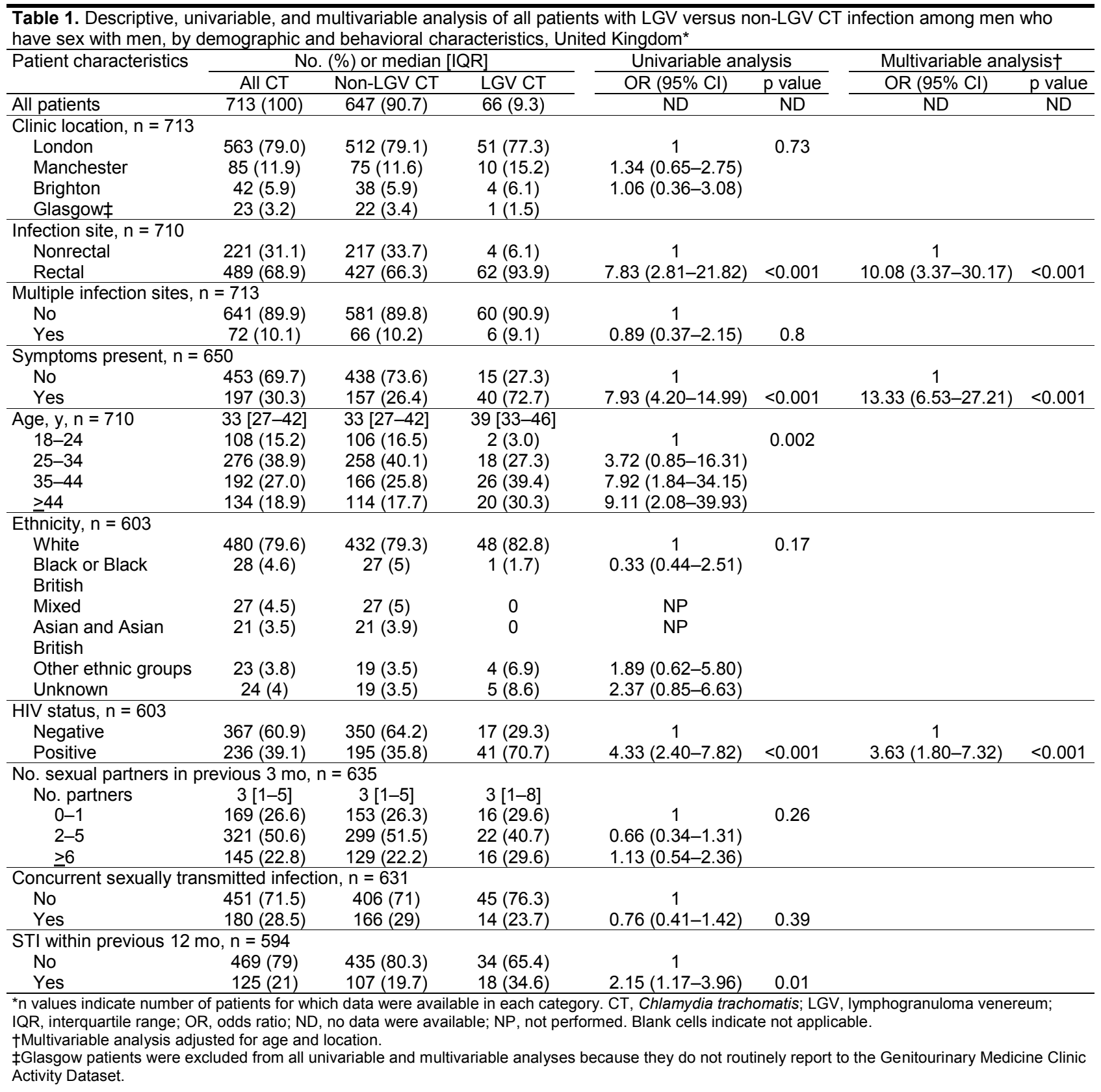


Table 2. Descriptive, univariable and multivariable analysis of patients in whom asymptomatic LGV CT or asymptomatic non-LGV CT infection was diagnosed, by demographic and behavioral characteristics, United Kingdom*

\begin{tabular}{|c|c|c|c|c|c|c|c|}
\hline \multirow{3}{*}{$\begin{array}{l}\text { Patient } \\
\text { characteristics }\end{array}$} & \multicolumn{3}{|c|}{ No. $(\%)$ or median [IQR] } & \multirow{2}{*}{\multicolumn{2}{|c|}{ Univariable analysis }} & \multirow{2}{*}{\multicolumn{2}{|c|}{ Multivariable analysis $\dagger$}} \\
\hline & \multirow{2}{*}{$\begin{array}{c}\text { All asymptomatic } \\
\text { CT }\end{array}$} & \multirow{3}{*}{$\begin{array}{c}\begin{array}{c}\text { Asymptomatic } \\
\text { non-LGV CT }\end{array} \\
414(96.5)\end{array}$} & \multirow{2}{*}{$\begin{array}{l}\text { Asymptomatic } \\
\text { LGV }\end{array}$} & & & & \\
\hline & & & & OR $(95 \% \mathrm{Cl})$ & $p$ value & OR $(95 \% \mathrm{Cl})$ & $p$ value \\
\hline All patients & $429(100.0)$ & & $15(3.5)$ & & & & \\
\hline \multicolumn{8}{|c|}{ Clinic location, $n=429$} \\
\hline London & $333(77.6)$ & $323(78.0)$ & $10(66.7)$ & 1 & 0.47 & & \\
\hline Manchester & $54(12.6)$ & $52(12.6)$ & $2(13.3)$ & $1.24(0.26-5.83)$ & & & \\
\hline Brighton & $26(6.1)$ & $24(5.8)$ & $2(13.3)$ & $2.69(0.56-12.99)$ & & & \\
\hline Glasgow & $16(3.7)$ & $15(3.6)$ & $1(6.7)$ & & & & \\
\hline \multicolumn{8}{|c|}{ Infection site, $\mathrm{n}=427$} \\
\hline Nonrectal & $129(30.2)$ & $126(30.6)$ & $3(20.0)$ & 1 & & & \\
\hline Rectal & $298(69.8)$ & $286(69.4)$ & $12(80.0)$ & $1.67(0.46-6.08)$ & 0.44 & & \\
\hline \multicolumn{8}{|c|}{ Multiple infection sites, $n=429$} \\
\hline No & $397(92.5)$ & $383(92.5)$ & $14(93.3)$ & 1 & & & \\
\hline Yes & $32(7.5)$ & $31(7.5)$ & $1(6.7)$ & $0.95(0.12-7.48)$ & 0.96 & & \\
\hline Age, $y, n=429$ & 33 [27-42] & $33[26-42]$ & 38 [29-44] & & & & \\
\hline $18-24$ & $73(17.0)$ & $72(17.4)$ & $1(6.7)$ & 1 & 0.64 & & \\
\hline 25-34 & $172(40.1)$ & $167(40.3)$ & 5 (33.3) & $2.19(0.25-19.07)$ & & & \\
\hline $35-44$ & $105(24.5)$ & 99 (23.9) & $6(40.0)$ & $3.72(0.43-32.59)$ & & & \\
\hline$\geq 44$ & $79(18.4)$ & 76 (18.4) & $3(20.0)$ & $2.8(0.28-27.55)^{\prime}$ & & & \\
\hline \multicolumn{8}{|l|}{ Ethnicity, $\mathrm{n}=378$} \\
\hline White & 302 (79.9) & $290(79.5)$ & $12(92.3)$ & 1 & 0.32 & & \\
\hline $\begin{array}{l}\text { Black or Black } \\
\text { British }\end{array}$ & $18(4.8)$ & $18(4.9)$ & 0 & NP & & & \\
\hline Mixed & $19(5.0)$ & $19(5.2)$ & 0 & NP & & & \\
\hline Asian and & $17(4.5)$ & $17(4.7)$ & 0 & NP & & & \\
\hline Asian British & & & & & & & \\
\hline $\begin{array}{l}\text { Other ethnic } \\
\text { groups }\end{array}$ & $13(3.4)$ & $13(3.6)$ & 0 & NP & & & \\
\hline Unknown & $9(2.4)$ & $8(2.2)$ & $1(7.7)$ & $3.02(0.35-26.13)$ & & & \\
\hline \multicolumn{8}{|c|}{ HIV status, $\mathrm{n}=378$} \\
\hline Negative & $235(62.2)$ & $231(63.3)$ & $4(30.8)$ & 1 & & & \\
\hline Positive & $143(37.8)$ & $134(36.7)$ & $9(69.2)$ & $3.88(1.17-12.84)$ & 0.03 & $3.91(0.92-16.66)$ & 0.06 \\
\hline \multicolumn{8}{|c|}{ No. sexual partners in previous $3 \mathrm{mo}, \mathrm{n}=401$} \\
\hline No. partners & $3[1-5]$ & $3[1-5]$ & $3[2-5]$ & & & & \\
\hline $0-1$ & $106(26.4)$ & $103(26.7)$ & $3(20.0)$ & 1 & 0.87 & & \\
\hline $2-5$ & $207(51.6)$ & $198(51.3)$ & $9(60.0)$ & $1.41(0.37-5.44)$ & & & \\
\hline$>6$ & $88(21.9)$ & $85(22.0)$ & $3(20.0)$ & $1.16(0.23-5.90)$ & & & \\
\hline \multicolumn{8}{|c|}{ Concurrent sexually transmitted infections, $n=398$} \\
\hline No & $295(74.1)$ & $283(73.7)$ & $12(85.7)$ & 1 & & & \\
\hline Yes & $103(25.9)$ & $101(26.3)$ & $2(14.3)$ & $0.47(0.10-2.12)$ & 0.32 & & \\
\hline \multicolumn{8}{|c|}{ STI during previous $12 \mathrm{mo}, \mathrm{n}=374$} \\
\hline No & $297(79.4)$ & $291(80.4)$ & $6(50.0)$ & 1 & & & \\
\hline Yes & $77(20.6)$ & $71(19.6)$ & $6(50.0)$ & $4.1(1.28-13.09)$ & 0.02 & $3.1(0.87-10.99)$ & 0.08 \\
\hline \multicolumn{8}{|c|}{$\begin{array}{l}\text { *n values indicate number of patients for which data were available in each category. CT, Chlamydia trachomatis; LGV, lymphogranuloma venereum; No., } \\
\text { number; IQR, interquartile range; Cl, confidence interval; OR, odds ratio; NP, not performed. Blank cells indicate not applicable. } \\
\text { †Multivariable analysis adjusted for age and location } \\
\text { †Glasgow patients were excluded from all univariable and multivariable analyses because they do not routinely report to the Genitourinary Medicine Clinic } \\
\text { Activity Dataset. }\end{array}$} \\
\hline
\end{tabular}

and $1(0.1 \%)$ equivocal; $4(0.4 \%)$ were not tested. CT infection was confirmed in 790 specimens from 713 patients; these specimens then underwent DNA typing. Overall, we found 69 (9\%) LGV CT-positive specimens from $66(9 \%)$ patients and $721(91 \%)$ non-LGV CT-positive specimens from 647 (91\%) patients (Table 1). Co-infection with LGV $\mathrm{CT}$ at 1 anatomic site and non-LGV CT at a different site was found in 4/713 $(0.6 \%)$ patients. Clinical data coordinating with the symptom checklist and GUMCADv2 were available for $95 \%(680 / 713)$ and $87 \%(603 / 690)$ of CTpositive patients, respectively. During the study period, GUMCADv2 recorded 1,097 CT diagnoses among 10,143
MSM screened at the 11 STI clinics in England, showing an estimated CT prevalence of $10.8 \%$.

Compared to those positive for non-LGV CT, patients with LGV CT infection were older and more likely to be symptomatic, to be HIV-positive, to have rectal infection, and to have had a previous STI diagnosis. In adjusted logistic regression analysis, symptomatic infection (adjusted odds ratio [aOR] 13.33; $\mathrm{p}<0.001$ ), rectal infection (aOR 10.08; $\mathrm{p}<0.001$ ) and being HIV-positive (aOR 3.63; $\mathrm{p}<0.001$ ) remained statistically significant (Table 1 ).

Of those with LGV for whom data were available, 27\% $(15 / 55)$ overall and $22 \%(12 / 54)$ with rectal-only infection 
were asymptomatic. Study prevalence of asymptomatic LGV was $2.3 \%(15 / 650)$ overall and 3.8\% (9/236) in HIVpositive MSM (Tables 1, 2).

Of the 15 patients with asymptomatic LGV, 12 (80\%) had rectal, $2(13 \%)$ urethral, and $1(7 \%)$ pharyngeal infections. All cases of asymptomatic LGV were from patients with single-site infection.

Among asymptomatic patients, those with LGV were more likely to be HIV-positive ( $69 \%$ vs. $31 \%$; odds ratio $3.88 ; \mathrm{p}=0.03)$ and to have had an STI in the past 12 months $(50 \%$ vs. $20 \%$; odds ratio $4.1 ; p=0.02)$ than those infected with non-LGV CT. These characteristics were only weakly associated in the adjusted analysis (aOR 3.91, $\mathrm{p}=0.06$, and aOR 3.1, $\mathrm{p}=0.08$, respectively).

\section{Conclusions}

This large multicenter case-finding study found a higher rate of asymptomatic LGV (27\%) than previously reported in the United Kingdom, in agreement with studies done in Germany and the Netherlands. LGV case-patients were typically older, white, HIV-positive MSM who had a concurrent or recent STI diagnosis. Most infections were rectal; few urethral and pharyngeal infections were detected.

The number of CT infections confirmed at the reference laboratory (713) was lower than those reported to national surveillance $(1,097)$, possibly related to differences in test sensitivity, degradation of CT DNA during transportation, or incorrect surveillance coding. No patients were excluded because of study restrictions; therefore, it is likely the study case-patients were representative of all MSM with diagnoses of CT infection in the United Kingdom.

More than one quarter of LGV cases in the United Kingdom may go undiagnosed if those who have asymptomatic chlamydial infection are not tested, as is the current strategy. Recommending that all CT-positive specimens from MSM be DNA tested for LGV serovars is unlikely to be cost-effective or feasible. However, because $3.8 \%$ of asymptomatic HIV-positive MSM had LGV (i.e., in excess of the recommended 3\% prevalence threshold for CT screening [13]), inclusion of these patients in the testing algorithm, as is done in Scotland (14), may be warranted.

Whether LGV symptomatology in the United Kingdom has changed or asymptomatic cases were previously missed is unclear. Changes in screening practice or selection pressure for asymptomatic infection after treatment of persons with symptomatic infection may have contributed. Most asymptomatic patients will be treated for non-LGV CT infection, but if treatment is suboptimal, it may not prevent onward transmission (15).

An undiagnosed reservoir of CT infection is unlikely to be the sole cause of the current epidemic. High-risk sexual behavior remains a substantive challenge for control of LGV and related epidemics among MSM (3). Future public health strategies will require a combined strategy of increased testing, prompt treatment, and continued promotion of safer sexual behavior among MSM.

Additional members of the UK LGV Case-Finding Group who contributed data: Sameena Ahmad (University Hospitals of South Manchester National Health Service [NHS] Foundation Trust, Manchester, UK) Nadia Ahmed, Patrick French (Central and North West London NHS Foundation Trust, London, UK); Sarah Alexander, Hemanti Patel, Pamela Saunders, Sinan Turkaslan (Sexually Transmitted Bacteria Reference Unit, Public Health England, Colindale, London); Tristan Childs, Stephen Duffell, Rishma Maini, Chinelo Obi, Parnam Seyan (Centre for Infectious Disease Surveillance and Control, PHE Colindale); Sara Day, Jamie Hardie, Ken McKlean, Alan McOwan, Christopher Scott, Richard Stack, Ann Sullivan (Chelsea and Westminster Hospital NHS Foundation Trust, London); Gillian Dean, Mohammed Hassan-Ibrahim, Gary Homer (Brighton and Sussex University Hospitals NHS Trust, Brighton, UK); Kirstine Eastick (Scottish Bacterial Sexually Transmitted Infections Reference Laboratory, Health Protection Scotland, Edinburgh, Scotland, UK); Laura Greaves, Maria Sampson, Merle Symonds (Barts Health NHS Trust, London); Rory Gunson, Anthony Rea, Andrew Winter (NHS Greater Glasgow and Clyde Health Board, Glasgow, Scotland, UK); Peter Horne, Daniel Krahe, Iain Reeves (Homerton University Hospital NHS Foundation Trust, London); Monica Rebec, Javier Rubio, Dawn Wilkinson (Imperial College Healthcare NHS Trust, London); Gabriel Schembri, Peter Tilston, Andrew Turner (Central Manchester University Hospitals NHS Foundation Trust); Simon Stevenson (University College London Hospitals NHS Foundation Trust); Helen Ward (Imperial College London); John White (Guy's and St. Thomas' NHS Foundation Trust, London).

Dr. Saxon is a consultant in sexual health and HIV in Manchester, UK. She completed this study during a joint fellowship of Public Health England and British Association of Sexual Health and HIV.

\section{References}

1. Götz H, Nieuwenhuis R, Ossewaarde T, Thio B, van der Meijden W, Dees J. Preliminary report of an outbreak of lymphogranuloma venereum in homosexual men in the Netherlands, with implications for other countries in western Europe. Euro Surveill. 2004;8:2367

2. Hamill M, Benn P, Carder C, Copas A, Ward H, Ison C, et al. The clinical manifestations of anorectal infection with lymphogranuloma venereum (LGV) versus non-LGV strains of Chlamydia trachomatis: a case-control study in homosexual men. Int J STD AIDS. 2007;18:472-5. http://dx.doi.org/10.1258/095646207781147319

3. Hughes G, Alexander S, Simms I, Conti S, Ward H, Powers C, et al. Lymphogranuloma venereum diagnoses among men who have sex with men in the UK: interpreting a cross-sectional study using an epidemic phase-specific framework. Sex Transm Infect. 2013;89:542-7. http://dx.doi.org/10.1136/sextrans-2013-051051 
4. Public Health England. Latest LGV surveillance data [cited 2015 Aug 21]. http://www.hpa.org.uk/Topics/InfectiousDiseases/ InfectionsAZ/LGV/

5. Ward H, Alexander S, Carder C, Dean G, French P, Ivens D, et al. The prevalence of lymphogranuloma venereum in men who have sex with men: results of a multicentre case finding study. Sex Transm Infect. 2009;85:173-5. http://dx.doi.org/10.1136/ sti.2008.035311

6. Spaargaren J, Fennema HAS, Morré SA, de Vries HJC, Coutinho RA. New lymphogranuloma venereum Chlamydia trachomatis variant, Amsterdam. Emerg Infect Dis. 2005;11: 1090-2. http://dx.doi.org/10.3201/eid1107.040883

7. Haar K, Dudareva-Vizule S, Wislinghoff H, Sailer A, Jansen K, Henrich B, et al. Lymphogranuloma venereum in men screened for pharyngeal and rectal infection, Germany. Emerg Infect Dis. 2013;19:488-92. http://dx.doi.org/10.3201/eid1903.121028

8. Annan NT, Sullivan AK, Nori A, Naydenova P, Alexander S, McKenna A, et al. Rectal chlamydia - a reservoir of undiagnosed infection in men who have sex with men. Sex Transm Infect. 2009;85:176-9. http://dx.doi.org/10.1136/sti.2008.031773

9. Ross J, Brady M, Clutterbuck D, Doyle T, Hart G, Hughes G, et al. British Association for Sexual Health and HIV recommendations for testing for sexually transmitted infections in men who have sex with men. London: BASHH; 2014 [cited 2015 Aug 21]. http://www.bashh.org/documents/BASHH\%20Recommendations $\% 20$ for $\% 20$ testing $\% 20$ for $\% 20$ STIs $\% 20$ in $\% 20$ MSM $\% 20-\% 20$ FINAL.pdf

10. Carder C, Mercey D. Benn P on behalf of the British Association for Sexual Health and HIV clinical effectiveness group. Chlamydia trachomatis UK testing guidelines 2010. London:
BASHH; 2010 [cited 2015 Aug 21]. http://www.bashh.org/ documents/3352.pdf

11. Ward H, Martin I, Macdonald N, Alexander S, Simms I, Fenton K, et al. Lymphogranuloma venereum in the United Kingdom. Clin Infect Dis. 2007;44:26-32. http://dx.doi.org/10.1086/509922

12. Public Health England. Genitourinary Medicine Clinic activity dataset (GUMCADv2): Guidance for clinic staff. London; PHE; 2013 [cited 2015 Aug 21]. https://www.gov.uk/genitourinarymedicine-clinic-activity-dataset-gumcadv2

13. Marrazzo JM, Celum CL, Hillis SD, Fine D, DeLisle S, Handsfield HH. Performance and cost-effectiveness of selective screening criteria for Chlamydia trachomatis infection in women: implications for a national chlamydia control strategy. Sex Transm Dis. 1997;24:131-41. http://dx.doi.org/10.1097/ 00007435-199703000-00003

14. White J, O'Farrell N, Daniels D. 2013 UK National guideline for the management of lymphogranuloma venereum: clinical effectiveness group of the British association for sexual health and HIV (CEG/BASHH) guideline development group. Int J STD AIDS 2013;24:593-601. http://dx.doi.org/10.1177/0956462413482811

15. Hathorn E, Opie C, Goold P. What is the appropriate treatment for the management of rectal Chlamydia trachomatis in men and women? Sex Transm Infect. 2012;88:352-4. http://dx.doi. org/10.1136/sextrans-2011-050466

Address for correspondence: Gwenda Hughes, STI Section, HIV \& STI Department, Centre for Infectious Disease Surveillance and Control, Public Health England Colindale, 61 Colindale Avenue, London, NW9 5EQ, UK; email: gwenda.hughes@phe.gov.uk

\section{July 2015: Malaria Including:}

- Disseminated Infections with Talaromyces marneffei in Non-AIDS Patients Given Monoclonal Antibodies against CD20 and Kinase Inhibitors

- Macacine Herpesvirus 1 in Long-Tailed Macaques, Malaysia, 2009-2011

- Malaria Prevalence among Young Infants in Different Transmission Settings, Africa

- Transdermal Diagnosis of Malaria Using Vapor Nanobubbles

- Lack of Transmission among Close Contacts of Patient with Case of Middle East Respiratory Syndrome Imported into the United States, 2014

- Monitoring of Ebola Virus Makona Evolution through Establishment of Advanced Genomic Capability in Liberia

- Parechovirus Genotype 3 Outbreak among Infants, New South Wales, Australia, 2013-2014

- MERS-CoV in Upper Respiratory Tract and Lungs of Dromedary Camels, Saudi Arabia, 2013-2014

- Assessment of Arbovirus Surveillance 13 Years after Introduction of West Nile Virus, United States

- Results from the National Legionella Outbreak Detection Program, the Netherlands, 2002-2012

http://wwwnc.cdc.gov/eid/articles/issue/21/07/table-of-contents 